\title{
Assessing lake-destination image: insights from the industry side
}

\author{
Ana Isabel Rodrigues, Antonia Correia and Metin Kozak
}

\section{Abstract}

Purpose - The literature review reveals that lake tourism and lake-destination areas (LDA) have been particularly absent from destination image (DI) studies over 45 years of research. In fact, there is a lack of research concerning the characteristics of lake tourism, particularly related to the attributes involved in the formation of lake-DI. Therefore, this paper aims to explore lake tourism and lake-DI based on the Alqueva Lake more thoroughly, it being the biggest man-made lake in Europe, as an emerging lake-destination area located in the south of Portugal.

Design/methodology/approach - Within this, theperceptions of stakeholdersprofessionally involved with this type of destination were examined through 17 semi-structured interviews based on content-analysis as a qualitative technique. Framed by the important contribution of visual-based research in tourism studies, this study adopts two approaches: an attribute-based approach (textual data) and a photo-based approach (visual data), to strengthen the concept, characteristics and dimensions of lake tourism and image attributes applied to this type of destinations. Multiple techniques of extracting data were used, demonstrating the importance of using various techniques in obtaining image attributes as a first step in assessing DIs.

Findings - The findings revealed textual and pictorial attributes related to lake tourism and LDA, which confirms that although image attributes are universally important, depicting specific attributes is important considering particular types of tourism, such as lake tourism.

Originality/value - This is a very recent sub-field of DI studies, which justifies its investigation on a theoretical as well as on a practical management level.

Keywords Destination image, Alqueva lake, Content-Analysis, Lake tourism, Lake-Destination areas Paper type Research paper

\section{Introduction}

Despite all the valuable resources that a place has which might contribute to its competitiveness in the world market, "strategic place marketing" is considered as the "most adaptive and productive approach to the problems of places" (Kotler et al., 1993, p. 20). The challenge with this "fresh approach", according to the authors, was to build up the capacity of regions to adapt to a changing marketplace, embrace opportunities and sustain their vitality. To have a distinctive product in a more competitive market, destinations need to entirely apprehend that image is an important element to be considered in any tourism development process (Morgan and Pritchard, 1998). Therefore, the present work is anchored on destination image (DI) theory produced since the early 1970s. Hunt's (1975) prominent work was decisive for the materialization of DI studies. Since that time, DI has been a vigorous research area (Rodrigues et al., 2012), which has been building theory and producing results.

A large number of studies have assessed DI in general, but few have attempted to measure it for any specific context (Pike, 2002). Despite the growing number of studies related to DI as the literature review demonstrates, very little is known about DI applied to the lake tourism context (Tuohino, 2006). In fact, regarding lake tourism, there is a lack of research

about its characteristics and also about the identification of attributes involved in the formation of lake-destination areas (LDA) image. For this reason, this study focuses on this particular type of destination, depicting image attributes most related to lake tourism and LDAs. This work is also underpinned by the fact that new destinations are emerging, and, therefore, it is important to broaden the scope of DI studies by investigating new types of tourism and destinations (Stepchenkova and Mills, 2010). Thus, lake tourism based on the Alqueva Lake as an emerging LDA located in the south of Portugal is explored more thoroughly.

This work also evaluates diverse explorative qualitative techniques as tools to identify image perceptions, based on the importance of pictorial elements in DI research. In sum, it attempts to answer the following research questions:

$R Q 1$. Which attributes are most relevant for the image formation of an LDA?

$R Q 2$. Which attributes of LDA best describe the Alqueva Lake as an emerging LDA?

$R Q 3$. What are the characteristics, dimensions and perceptions of lake tourism and the Alqueva Lake as an emerging LDA?

\section{Literature review}

It is important to note that lakes are open water bodies, dams or reservoirs which might represent a valuable resource for a variety of human activities. In addition, lakes might also become an important resource for tourism development, based on their landscape features and cultural attractions. Lakes offer a naturally defined core resource for tourism development, defined as "tourism that occurs not only on the lake itself, but also in the surrounding area [. . . include the lake, the foreshore and those amenities, facilities and infrastructure [. . .]" (Hall and Harkonen, 2006, p. 4). Actually, despite the natural and cultural resources around the lake, the general enchantment of lakes relates to human emotions and how lakes make tourists feel is of utmost importance.

For this, lake environment, specially waterscapes, increasingly represent an important resource for tourismbecause oftheir pleasantness and an environment and attractiveness as a landscape (Tuohino and Pitkanen, 2004). Consequently, assessing meanings and perceptionsthattourists have offeel aboutalakeemergesas an interestingfield toexplore for tourismmarketing. The image ofalake and depicting image attributes becomes crucial because a strong image is integral to successful marketing plans for lakes (Erkkila, 2006; Ryhanen, 2001; Tuohino, 2006). In this sense, image is revealed as an important element when defining lake tourism. Ryhanen (2001) stresses the relevance of forming a lake-DI when tourists decide to travel to an LDA. Based on this line of thought, image studies related to lake tourism and LDA are required and justified for a successful marketing strategy. 
Nevertheless, the research published related to this new academic field is scarce. Some previous research focused on lake landscape representations, particularly the Finnish lakes (Pitkanen and Vepsalainen, 2006) or the development of lake tourism in The Netherlands (Goossen, 2006) in general. To date and particularly related to image, it is worth mentioning the only studies published in this field (Tuohino and Pitkanen, 2004; Tuohino, 2006). These authors brought to light the importance of assessing perceptions aboutlakes and demonstrated itcan becrucial forlake tourismmarketingbecauseitallows the transformation of aneutral landscape intoameaningful experience. In other words, the assessment of lake images allows us toadd meanings tothe lakes, justifying why they are so important for lake tourism development. However, these studies did not depict image attributes more specifically. For that, more studies are needed, as argued by Tuohino (2006, p. 101), "as for lake tourism, destination marketing has only barely started".

Therefore, this study is based on the assumption that DI, owing to its simplicity, dynamism and capacity to integrate several factors, might represent a key element for the development and management of destinations (Rolo-Vela, 2009). Simultaneously, image as a marketing variable might actually influence the tourism development of a certain destination. According to Font (1997, p. 123), "a tourist destination's image is one of the most important strategic tools for creating and sustaining tourist destinations". In sum, image is considered a key construct in destination positioning (Pike and Ryan, 2004). Image analysis and management is, in fact, a key tool for destination competitiveness.

Given the above, exploring the characteristics of lake tourism and LDAs and simultaneously depicting attributes that are most relevant for the image formation of this type of destinations emerges as a fundamental issue. Even more so when a new trend in DI research emerged in the 2000s and non-traditional entities started to be assessed, such as the image of specific types of tourism and destinations (e.g. mountain tourism, Silva et al., 2013; or rural-cultural excursion destinations, Rolo-Vela, 2009). In fact, a large number of studies have assessed DI in general, but few have attempted to measure it for any specific context (Pike, 2002). In this case, as lake tourism and LDAs have been completely absent from DI studies, the need for a DI study specifically related to this recent type of tourism is justified.

$\mathrm{DI}$ is considered a multidimensional phenomenon that includes not only the demand side,

i. e. what is perceived and understood by the tourists, but also the supply side, i.e. what is communicated by the destination from the stakeholder's perspective (Martfn and Rodriguez del Bosque, 2008). The decision for this study was to focus on the supply image,

i. e. the stakeholder's opinion. However, this is only a part of a more extensive work which will assess the tourist's perceptions as the next stage. In addition, the literature demonstrates thattheconstructofDllies attheverycenterofmultiitem constructs (Fakeye and Crompton, 1991). Different components are used to define, and consequently, to measure this construct. The consumer is assumed to evaluate the destination attribute by attribute. Consequently, DI research was mainly characterized by a predominance of the quantitative approach (Gallarza et al., 2002).

Nevertheless, alternative methods of measuring DI soon come to light as a consequence of a new cycle in terms of DI theorizing. New methodological procedures based on qualitative methods (Jenkins, 1999) were proposed, such as the example of free-elicitation technique(Reilly, 1990) orvisual-based studies(Jacobsen, 2007). Thesenewperspectives on DI research, which arose in the 1990s and were strengthened in the 2000s, contribute to exploring new ways of communicating image attributes such as the pictorial element. Soon, several photo-based studies emerged, using photographs in DI measurement (Fairweather and Swaffield, 2002). One of several possibilities for using photographs is to include them in questionnaires and/or personal interviews so they might be used as stimuli (Jacobsen, 2007). Thus, this study is also framed by a photo-based approach based on visual data.

Finally, it is expected that the results of this study will be useful for the regional destination management organization (DMO), which has a crucial role in defining a successful marketing strategy for the lake under study.

Research methodology

This paperis part of a multistage research, where the perceptions ofthesupplyside, in this casestakeholders, professionallyinvolved with this typeofdestination were examined. The demand side, the actual tourists, will be analyzed in the next stage of this research. In the present study, the aim was to assess the applicability of image attributes related to lake tourism extracted in previous studies and also generate new ones to identify attributes that might be included in a lake image scale in the future. In addition, apprehending the concept and characteristics of lake tourism and LDA was also defined as a goal. As DI is a very complex construct, the importance of using various techniques, framed by a qualitative approach, soon became evident. Moreover, the literature review demonstrated that there are advantages in using different qualitative techniques because it apprehends more aspects of image (Jenkins, 1999).

To assess a list of items related to lakes, the study was conducted at the Alqueva Lake. This is because of the fact that this lake is the largest reservoir in Europe (surface area $250 \mathrm{~km}^{2}$; maximum depth $99 \mathrm{~m}$; shoreline 1,200 km; length $82 \mathrm{~km}$ ) since the gates of the dam were closed in 2002. Because this is a new lake in this region, the idea was also to contribute more effectively to a better understanding of the Alqueva Lake in present times. The regional DMO is defining the marketing strategy for the lake until 2020.

Given this, 17 semi-structured interviews were carried out. Various experts professionally involved with the tourism industry were selected as key informants representing various sectors (Table I). The purpose was to embrace different perspectives about the reality of the destination under study. The interviews incorporate two approaches: an attribute-based approach (textual data) and also a photo-based approach (visual data), specifically with photographs of the Alqueva Lake. Based on the goals of the study, the structure of the interview consisted mainly of two sections. The first was a more structured part with the aim to cover the first and the second research questions. In this case, three techniques of extracting data were used (checklist, free-elicitation and photo-elicitation). The second section consisted of seven open-ended questions, which aimed to answer $R Q 3$ by exploring the nature of lake tourism as a form of tourism. The data were content-analysed using WebQDA (Web Qualitative Data Analysis), software which carries out qualitative data analysis individually or collaboratively, synchronously or asynchronously (Souza et al., 2011).

Regarding the checklist, a comprehensive set of image attributes related to LDA was listed across a table as a common method for data collection in DI studies. In this case, the respondents were asked to rate their importance for lake tourism and also if they describe the Alqueva Lake as an LDA. The items included in the table were predetermined from Rodrigues et al.'s results (2015), considering that a list of image attributes specifically related to LDAs was identified by the authors. 



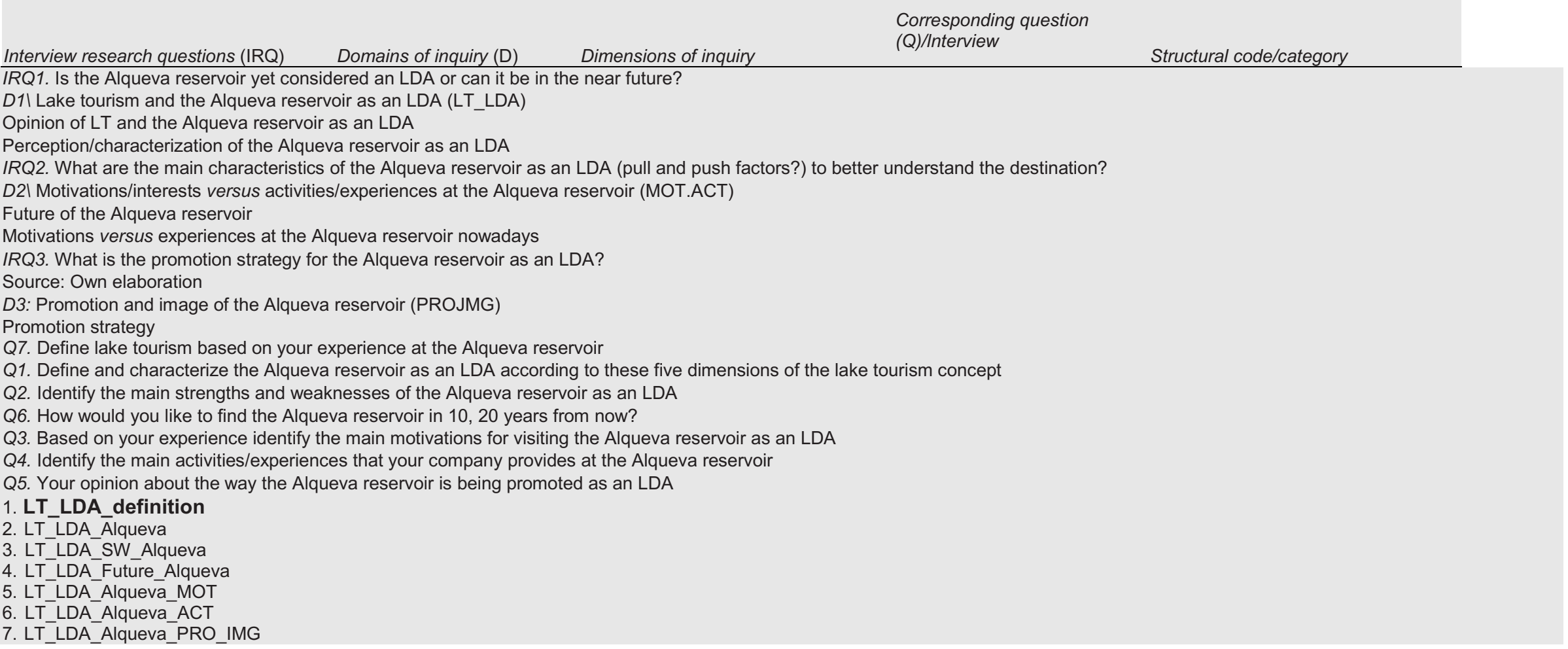





\section{Checklist technique}

The structured approach of this interview involved a list of attributes related to LDAs classified according to nine image dimensions (Beerli and Marfin, 2004). To assess the applicability of these items, two levels of assessment were developed:

1. if the items are important for image formation of an LDA; and

2. if those items described the Alqueva Lake as an LDA. According to the respondents most of the items on the list were judged to be important for LDAs.

The findings suggest that the image formation of an LDA is deeply rooted in the development of a lake for tourism purposes which comprises the lake itself as a natural resource and also the surrounding region. The image attributes are related to nautical activities (e.g. "houseboating", "fishing"), along with activities at the surrounding region (e.g. "themed events", "organized tours"). The same occurs with image attributes associated with infrastructures on the lake itself (e.g. "marinas", "ports", "public ramps") along with the territory where the lake is located (e.g. "rural houses", "restaurants and cafes", "visitor centres"). Two additional observations emerge:

1. the "qualityofthe lake water" isdefinitelyone of the most relevant attributes that should be considered in promotional campaigns; and

2. the existence of psychological attributes most linked with the atmosphere of the lake (e.g. "hospitable atmosphere", "picturesque and traditional", "friendly and family-oriented").

The findings from the checklist technique also reveal that the image attributes that best describe the Alqueva Lake are associated with natural and cultural resources (e.g. "local dishes/gastronomy", "historical villages", "landscape") and atmosphere of the lake (e.g. "picturesque and traditional", "peaceful, quiet and relaxing", "presence of local people"), which are in line with the main ideas extracted from lake tourism definitions. The surrounding region, where the lake is located, might add a significant value to this type of tourism, whereupon these results seem to demonstrate that this lake has potential as an LDA.

Free-elicitation and photo-elicitation technique

To respond to the first and also second goal, the outcomes of these two techniques are presented in word clouds as a visual representation of text and pictorial data in a free format.

First, through the free-elicitation technique, respondents were able to provide descriptors of LDAs, specifically the Alqueva Lake as the illustrative case. Data analysis consisted of using the word cloud, particularly the frequency type, where word size represents the number of times that an attribute (keyword) has been applied to a single item. Here, the image attributes extracted were salient to the respondent rather than imposed by the researcher (Reilly, 1990). Three main considerations were broughtoutfrom the word cloud in Figure 1. At first glance, attributes were depicted from the functional to psychological continuum (e.g. "climate", "islands", "landscape", "shoreline", "heritage" vs "vastness", "silence", "diversity"). Second, it was curious to note that the attribute "vastness" was the most cited by the respondents because it refers more to feelings and sensations associated with the lake, in particular the landscape as a resource. Thus, this attribute is deeply linked with the surface of the lake because it is the biggest man-made lake in Europe. Lastly, and corroborating the results from previous phase, the depicted attributes reflect the definition of lake tourism. Some of them are linked with the lake itself (e.g. "water", "shorelines", "islands", "houseboating"), but others are associated with the surrounding region (e.g. "landscape", "nature", "history"). In conclusion, this word 


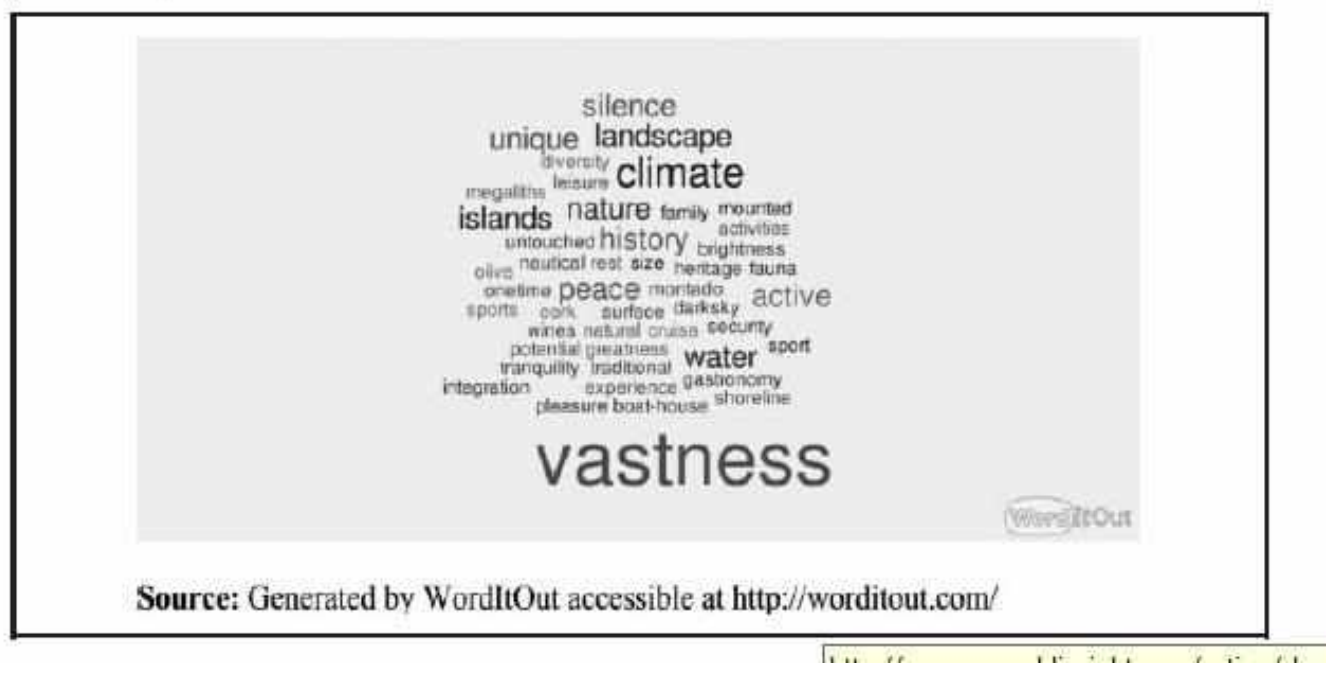

Source: Generated by WordltOut accessible at http://worditout.com/

association technique gave more attributes related more to the atmosphere dimension of image (Beerli and Martfn, 2004) among the respondents.

As explained before, in a more photo-based approach with the photo-elicitation technique, five categories were used to represent image dimensions of LDA (Rodrigues et al., 2015). Plate 1 was developed from the highest ranked photos together with the respondent's descriptions. Overall, thephotoelicitation resultsare entirelyin line with the results from the free-elicitation technique. The consistent presence of water in the landscape evokes feelings and memories that could be used when promoting the Alqueva Lake. A final remark is reserved for items such as "experiences", "activities", "nature" and "nautical", meaning thatexperiencing thelake through nautical activitiesis ofutmost importance when promoting this resource.

The following are the main resultsoftheopen-ended questions, which aimed toobserve characteristics of lake tourism and LDAs, particularly the Alqueva Lake, and the attributes that potentially influence this type of destination. In fact, an effort was made to understand not only the manifest (e.g. counting words) but also latent content data. The inferences and deductions presented here are intended to be valuable primarilyas end-products and, second, as entry points for further study. However, because of the great amount of data (this inductive approach generated 34 key-ideas related to lake tourism), a more "focusing strategy" is needed (Saldana, 2009) to select a limited number of the various ideas that emerge from the open-ended questions. The following topics are derived from the first and second level of content analysis:

Structural coding: "Lake tourism definition" Several ideas arose related to this topic, which are in line with the literature review of lake tourism. Most of the respondents gave a definition of lake tourism, mostly based on three main topics:

1. Lakes as a resource-based tourism attraction demands high levels of management and coordination, which corroborates Cooper's (2006) main concern about lake tourism development.

2. Lakes are considered an important resource for tourism development.

3. The value added by the attractions located in the surrounding region. One of the respondents stated that "Alqueva has a set of natural resources, the landscape itself, the scale, the topography of the lake [. . .]" [R6]. 
Pinte 1 Erimples of photes that bast portmy the Alquora lake as an L.DA per category with the respondents deseription (shoto alicitation)
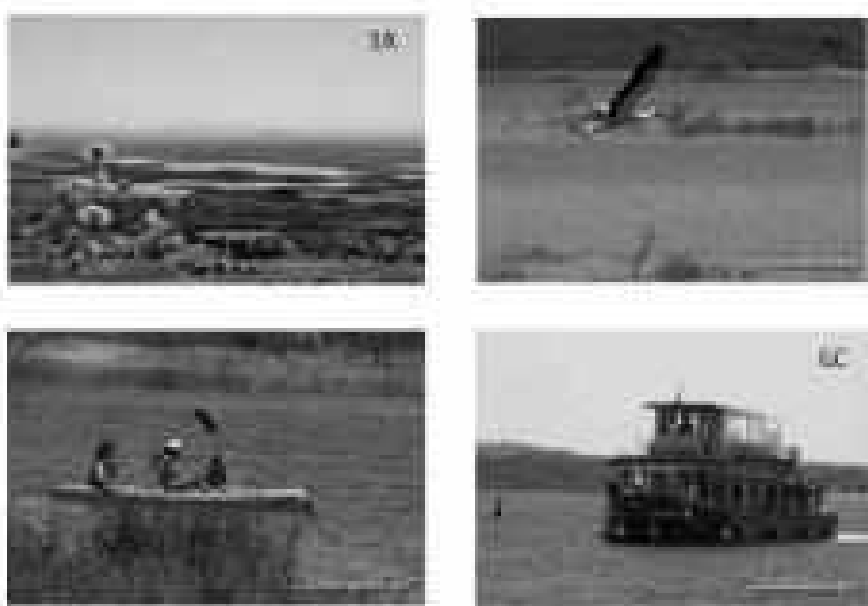

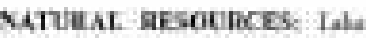
carben tartom. las inirves.

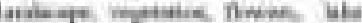

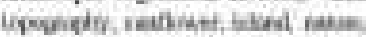

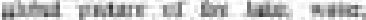
inamen anos flan. bas

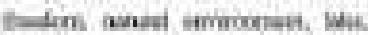

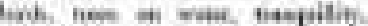

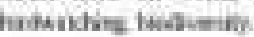
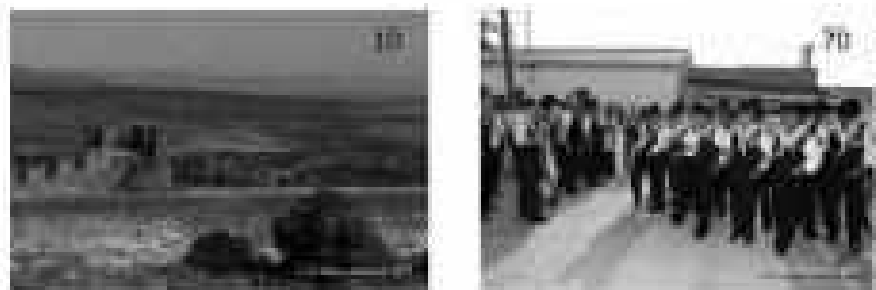

CULTURE AND HERISGE

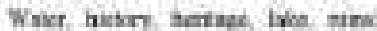

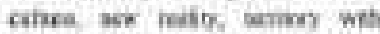

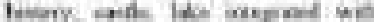
tesery gise acher. raditio.

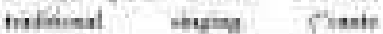

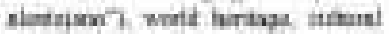
tertales luary
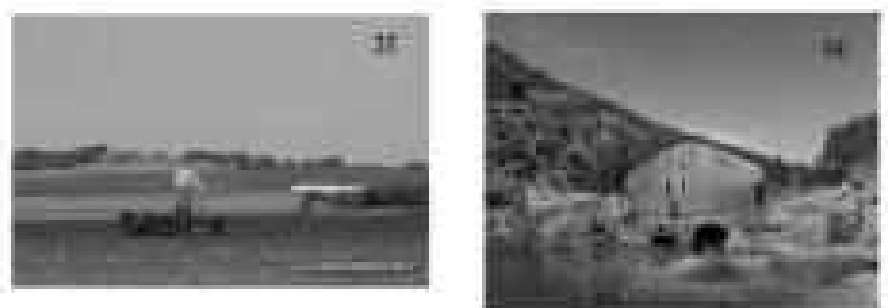

ATMosphenE Troling.

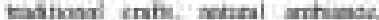

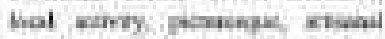
fibieg. scthescans sennows

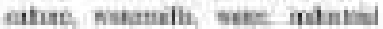
hariage hieing lankerge and Ninar, tove hasry
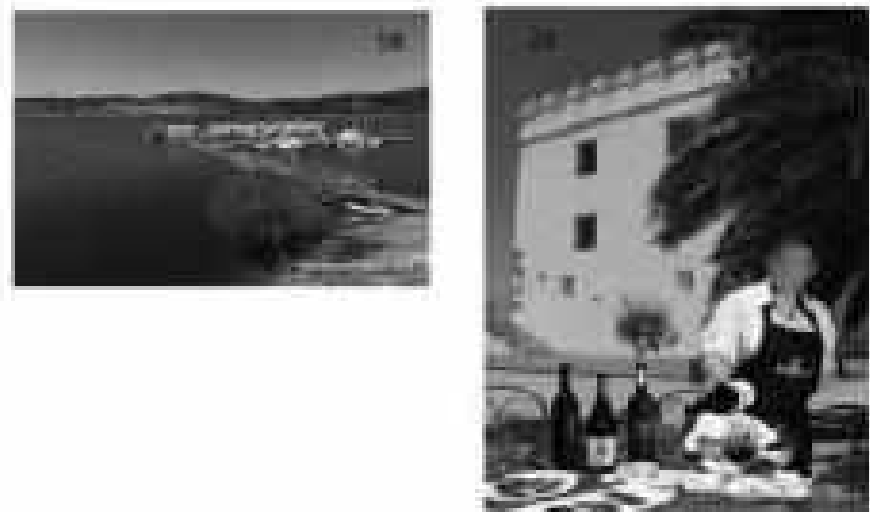

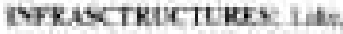

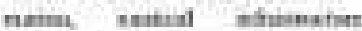

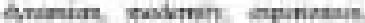

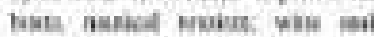

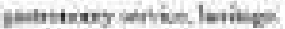

Source: Official pbotes from the former DMO of the Alqueva reservoir (TGLA) with permission

Source: Official photos from the former DMO of the Alqueva reservoir (TGLA) with permission Structural coding: "Perception/Characterization of the alqueva reservoir as an LDA The results 
corroborate the literature review about lake tourism dimensions. It was possible to identify key ideas important for the development of lake tourism such as the existence of natural and cultural resources; the importance of "tourist signage", "quality of roads" and "transport facilities" to and around the lake; the existence of "nautical infrastructures"; "tourist leisure and recreation"; "tourist infrastructure"; and "tourist services and information about the lake". These clearly identify important elements for the development of lake tourism. Here are some examples from the respondents: "In terms of nautical infrastructures there's only a marina, and some piers at the riparian villages [ . . ]" [R1] or "[ . . ] signage is linked to accessibility. The Alqueva lake is very poorly signed [. . .]" [R8].

Structural coding: "Promotion and image of the Alqueva reservoir" This idea is related to $R Q 3$ of the interview "What is the promotion strategy for the Alqueva Lake as an LDA?". The goal here was to identify if there was any strategic purpose for this lake, considering that it is the very beginning of the life cycle model. This is considered to be an important factor to identify the characteristics of the Alqueva Lake. The analytic process brought out two main topics: information about the strategy and extracting elements that might contribute to differentiating the Alqueva Lake as an LDA. The purpose was to help the DMO to find a suitable and effective positioning for this area in the near future. Related to this a respondent said:

"There has to be integrated management. I cannot continue to sell dreams. We need to have a master plan for the lake that defines the concept and products ([. . .])" [R1]

\section{Conclusions and implications}

The results obtained here confirm the existence of a particular type of tourism based on natural/or artificial lakes that takes place not only on the lake itself but also in the surrounding region. Considering the importance that image as a strategic tool has for the development of destinations, particularly in the very beginning of their life cycle, conceptualizing this type of tourism reinforces the need to develop an image measurement scale which is more adapted to LDA. In fact and in line with other researchers' conclusions (Rolo-Vela, 2009), the findings confirmed that although there are universally important image attributes, other attributes are only relevant for specific types of tourism. In fact, such an image measurement scale could be used as a tool for conceiving a management model for LDAs, considering their particularities revealed by the content analysis results based on the case of the Alqueva Lake have.

Based on Beerli and Marfin's classification (Beerli and Marfin, 2004), the findings also show that different techniques gave similar types of attributes more related to atmosphere as an image dimension (e.g. "peaceful and relaxing", "security", "immensity") and more attribute-based images (e.g. "landscape", "nature", "water", "activities") more related to other dimensions (e.g. activities, natural resources). These results were combined with open-ended questions, where the respondents had the opportunity to explain better their opinions. This is considered to be an advantage of using various techniques in obtaining image attributes as a first stepin analyzing images. Additionally, photoelicitation exposed not only attributes regarding atmosphere but also more objective attributes, whereas the free-elicitation showed more tangible types of image dimensions.

As aresult ofthe qualitative datacollection phase, mainlyfromthe checklisttechnique, the applicability of 44 image attributes that potentially influence the image formation of LDAs was assessed. This set of items includes both functional-psychological and attribute-holistic types of images and several image dimensions. Simultaneously, a set of 37 variables that best describe the Alqueva Lake as an LDA was obtained. Some managerial implications concerning the promotion and positioning of the LDA should be outlined. One ofthe most important challenges when promoting an LDA is to recognize its strengths and weaknesses. A qualitative study as this can help to explore the complexity ofimages more, especially in the case ofdestinations that are at the verybeginning of the life cycle, such as the Alqueva Lake. An image assessment study in this stage might contribute to maintaining or reinforcing the strengths and improving the attributes where main weaknesses were detected.

A more structured methodology applied now to tourists will allowto recognize in the future if the perceived image of an LDA, the Alqueva Lake in this case, coincides or not with its projected image according to the stakeholders. There is no doubt that knowing the perceptions and motivations is fundamental in tourist decisions and is crucial in the formation of a DI (Correia and Crouch, 2003). Finally, future research should be directed toward a reliable scale of image measurement for LDAs. The line of action should strategically enhance the image, positioning and competitive advantage of such types of destination, demanding image studies as a precondition of further decisions and based on the concept of a Lake Wellness product (Konu et al., 2010). 


\section{References}

Beerli, A. and Martin, J.D. (2004), "Factors influencing destination image", Annals of Tourism Research, Vol. 31 No. 3, pp. 657-681.

Choi, S., Lehto, X.Y. and Morrison, A.M. (2007), "Destinationimagerepresentationontheweb:content analysis of Macau travel related websites", Tourism Management. Vol. 28, pp. 118-129.

Cooper, C. (2006), "Lakes as tourism destination resources", in Hall, C.M. and Harkonen, T. (Eds), Lake Tourism: An Integrated Approach to Lacustrine Tourism Systems, Channel View Publications, Aspects of Tourism, Vol. 32, pp. 27-42.

Correia, A. and Crouch, G. (2003), "Tourist perceptions of and motivations for visiting the Algarve, Portugal", Tourism Analysis, Vol. 8 Nos 2/4, pp. 165-169.

DeSantis, L. and Ugarriza, D.N. (2000), "The concept of theme as used in qualitative nursing research", Western Journal of Nursing Research, Vol. 22 No. 3, pp. 351-372.

Erkkila, D.L. (2006), "Local considerations in marketing and developing lake-destination areas", in Hall, C.M. and Harkonen, T. (Eds), Lake Tourism. An Integrated Approach to Lacustrine Tourism Systems, Channel View Publications, Aspects of Tourism, Vol. 32, pp. 207-222.

Fairweather, J.R. and Swaffield, S.R. (2002), "Visitors' and locals' experiences of Rotorua, New Zealand: an interpretative study using photographs of landscapes and Q method", International Journal of Tourism Research. Vol. 4, pp. 283-297.

Fakeye, P.C. and Crompton, J.L. (1991), "Image differences between prospective, first-time, and repeat visitors to the lower Rio Grande valley", Journal of Travel Research. Vol. 30 No. 2, pp. 10-16.

Font, X. (1997), "Managing the tourist destination's image", Journal of Vacation Marketing. Vol. 3 No. 2, pp. 123131.

Gallarza, G., Saura, G. and Garcia, H. (2002), "Destination image: towards a conceptual framework”, Annals of Tourism Research, Vol. 29 No. 1, pp. 56-78.

Goossen, M. (2006), "Lake tourism in the Netherlands", in Hall, C.M. and Harkonen, T. (Eds), Lake Tourism: An Integrated Approach to Lacustrine Tourism Systems, Channel View Publications, Aspects of Tourism, Vol. 32, pp. 119-130.

Hall, C.M. and Harkonen, T. (2006), "Lake tourism: an introduction to lacustrine tourism systems", in Hall, C.M. and Harkonen, T. (Eds), Lake Tourism: An Integrated Approach to Lacustrine Tourism Systems, Channel View Publications, Aspects of Tourism, Vol. 32, pp. 27-42.

Harper, D. (2002), "Talking about pictures: a case of photo elicitation", Visual Studies, Vol. 17 No. 1, pp. 13-26. Hunt, J.D. (1975), "Image as a factor in tourism development", Journal of Travel Research, Vol. 13, pp. 1-7. Jacobsen, J.K.S. (2007), "Use of landscape perception methods in tourism studies: a review of photo-based research approaches", TourismGeographies:AnInternationalJournalofTourismSpace, Place and Environment, Vol. 9 No. 3, pp. 234-253.

Jenkins, O.H. (1999), "Understanding and measuring tourist destination images", International Journal of Tourism Research, Vol. 1, pp. 1-15.

Konu, H., Tuohino, A. and Komppula, R. (2010), "Lake wellness a practical example of anewservice development (NDS) concept in tourism industries", Journal of Vacation Marketing, Vol. 6 No. 2, pp. 25-39.

Kotler, P., Haider, D.H. and Rein, I. (1993), MarketingPlaces, Free Press, New York, NY.

Marfln, H.S. and Rodnguez del Bosque, I.A. (2008), "Exploring the cognitive-affective nature of destination image and the role of psychological factors in its formation", Tourism Management, Vol. 29, pp. 263-277.

Morgan, N. and Pritchard, A. (1998), Tourism, Promotion and Power: Creating Images, Creating Identities, Wiley, Chichester.

Namey, E., Guest, G., Thairu, L. and Johnson, L. (2008), "Data reduction techniques for large qualitative data sets", in Guest, G., MacQueen, K.M. (Eds), Handbook for Team-Based Qualitative Research, Altamira Press, pp. 137-161.

Olson, J.C. and Muderrisoglu, A. (1979), "The stability of responses obtained by free elicitation: implications for measuring attribute salience and memory structure", Advances in Consumer Research, Vol. 6, pp. 269-275. Pike, S. (2002), "Destination image analysis: a review of 142 papers from 1973 to 2000", Tourism Management, Vol. 23, pp. 541-549.

Pike, S. and Ryan, C. (2004), "Destination positioning analysis through a comparison of cognitive, affective, and conative perceptions", Journal of Travel Research, Vol. 42 (May), pp. 333-342.

Pitkanen, K. and Vepsalainen, M. (2006), "The changing historical dimensions of lake tourism at Savonlinna: Savonlinna - the pearl of the Saimaa, Lake representations in the tourist marketing of Savonlinna", in Hall, M. and Harkonen, T. (Eds), Lake Tourism. An Integrated Approach to Lacustrine Tourism Systems, Channel View Publications, Clevedon, pp. 67-82.

Prebensen, N.K. (2007), "Exploring tourists' images of a distant destination", Tourism Management, Vol. 28, pp. 747-756.

Reilly, M.D. (1990), "Free elicitation of descriptive adjectives for tourism image assessment”, Journal of Travel Research, Vol. 28 No. 4, pp. 21-26.

Rodrigues, A., Correia, A. and Kozak, M. (2012), "Exploring the life-cycle model applied to 'umbrella constructs': destination image as an example", Tourism Recreation Research, Vol. 37 No. 2, pp. 133-143.

Rodrigues, A., Correia, A., Kozak, M. and Tuohino, A. (2015), "Lake-destination image attributes: content analysis of text and pictures", in Correia, A., Gnoth, J., Kozak, M. and Fyall, A. (Eds), Advances in Marketing Places and Spaces, Book series: Advances in Culture, Tourism and Hospitality Research, Emerald Group Publishing Limited, 
Vol. 10, pp. 293-314.

Rolo-Vela, M. (2009), "Rural-cultural conceptualization: a local tourism marketing management model based on tourism destination image measurement", Tourism Management, Vol. 30, pp. 419-428.

Ryhanen, H. (2001), "The touristic profile and potential of European lake destinations", Paper Presented at ATLAS 10th Anniversary International Conference, 4-6 October 2001, Dublin.

Saldana, J. (2009), The Coding Manual for Qualitative Researchers, Sage.

Silva, C., Kastenholz, E. and Abrantes, J.L. (2013), "Place-attachment, destination image and impacts of tourism in mountain destinations", Anatolia: An International Journal of Tourism and Hospitality Research, Vol. 24 No. 1, pp. 17-29.

Souza, N.F., Costa, A.P. and Moreira, A. (2011), "Web qualitative data analyses -WebQDA (Version 2.0)

[Software]", Aveiro: Centro de Investigagao Didatica e Tecnologia na Formagao de Formadores da Universidade de Aveiro e Esfera Crttica, available at: www.webqda.com/

Stepchenkova, S. and Mills, J.E. (2010), "Destination image: a meta-analysis of 2000-2007 research", Journal of Hospitality Marketing \& Management, Vol. 19, pp. 575-609.

Tuohino, A. (2006), "Lakes as an opportunity for tourism marketing: in search of the spirit of the lake", in Hall,

C.M. and Harkonen, T. (Eds), Lake Tourism: An Integrated Approach to Lacustrine Tourism Systems, Channel View Publications, Aspects of Tourism, Vol. 32, pp. 101-118.

Tuohino, A. and Pitkanen, K. (2004), "Selling waterscapes?", in Saarinen, J. and Hall, C.M. (Eds), Nature-Based Tourism Research in Finland: Local Contexts Global Issues, Finnish Forest Research Institute, Finland, Vol. 916, pp. 129-150.

Ye, H. and Tussyadiah, P. lis (2011), "Destination visual image and expectation of experiences", Journal of Travel and Tourism Marketing, Vol. 28 No. 2, pp. 129-144.

Further reading

Crouch, G. and Ritchie, J. (2000), "The competitive destination: a sustainability perspective", $\underline{\text { Tourism }}$

Management, Vol. 21 No. 1, pp. 1-7.

Dann, G. (1996), "Tourists' images of a destination - an alternative analysis", Journal of Travel and Tourism Marketing, Vol. 5, pp. 41-55.

Echtner, C. and Ritchie, B. (1991), "The meaning and measurement of destination image", Journal of Tourism Studies, Vol. 2 No. 2, pp. 2-12.

Echtner, C. and Ritchie, B. (1993), "The measurement of destination image: an empirical assessment", Journal of Travel Research, Vol. 31 No. 4, pp. 3-13.

About the authors

Ana Isabel Rodrigues is Assistant Professor of Tourism, Polytechnic Institute of Beja, Portugal. She holds a degree in Social and Cultural Communication from the Catholic University of Lisbon and a master's degree in Communication and Destination Image from ISCTE-Lisbon University Institute. She is currently a PhD candidate at Algarve University. Her research is focused on destination marketing and image formation, particular in lake-destination areas. Ana Isabel Rodrigues is the corresponding author and can be contacted at: ana.rodrigues@ipbeja.pt

Antonia Correia is Professor of Tourist Behavior and Tourism Economics, University of Algarve, and Member of CEFAGE, in Portugal. Her main research interests focus on consumer behavior, tourism economics and modeling. She has a number of papers published in tourism, leisure and economics journals. Antonia is also a member of the editorialboard of several journals including Journal of Travel Research, Journal of Business Research, Tourism Analysis and Anatolia.

Metin Kozak is Professor of Tourism in the School of Tourism and Hospitality Management, Dokuz Eylul University, Turkey. He holds both master's and PhD degrees in Tourism Management. His research focuses on consumer behavior, benchmarking, destination management and marketing, sustainability and Mediterranean tourism. He acts as the co-editor of Anatolia: An International Journal of Tourism and Hospitality Research and has been to various universities as a visiting scholar.

Rodrigues, A., Correia, A., Kozak, M. (2017). Assessing lake-destination image: Insights from the industry side. International Journal of Culture, Tourism and Hospitality Research, 11(1), pp. 5-17. https://doi.org/10.1108/JJCTHR-09-2015-0116

\section{Versão do editor disponível em: https://doi.org/10.1108/IJCTHR-09-2015- 0116}

